Proc. Estonian Acad. Sci. Eng., 2003, 9, 3, 157-184

\title{
An experimental study of wind waves and ship wakes in Tallinn Bay
}

\author{
Tarmo Soomere and Kalev Rannat
}

\author{
Marine Systems Institute, Tallinn Technical University, Akadeemia tee 21, 12618 Tallinn, Estonia; \\ tarmo@phys.sea.ee
}

Received 1 April 2003, in revised form 14 June 2003

\begin{abstract}
The results of a field study of wind waves and ship wakes in the coastal area of Tallinn Bay in the years 2001-2002 are described. The main goal was to identify the typical and extreme parameters of ship wakes and to describe their energetic properties in different coastal areas. The basic features of wind wave fields in different wind conditions are estimated. The structure of the wake patterns of fast ferries, the maximum and typical values of wake heights and their spatial variability are analysed. Waves caused by fast ferries generally are higher than those excited by hydrofoils or conventional ferries. Their daily maximum height typically exceeds $1 \mathrm{~m}$ and may reach in extreme cases $1.7-2.3 \mathrm{~m}$ at a depth of $5 \mathrm{~m}$ at the eastern coast of the bay. The highest wave components frequently have periods of $10-15 \mathrm{~s}$. Waves with such properties do not occur in natural conditions in the area in question. The spatial variation of the average energy density of the ship waves and its flux is relatively small in Tallinn Bay. The daily average frequency spectra of shipgenerated waves show that different parts of the coastal zone are affected by waves with largely different properties.
\end{abstract}

Key words: wind waves, high-speed craft, wake wash, wave measurements, wave spectra, semienclosed seas.

\section{INTRODUCTION}

Waves critically intersect with the interests of mariners and society both in open sea and coastal regions. Preventing beach evolution, designing and building structures, designing and operating ships, providing marine forecasts, and coastal planning are just a few examples of activities for which extensive information about wave conditions is critical. Scientific studies, especially those involving coastal processes and the development of better wave prediction models, also require correct wave information. 
However, wave conditions along and off the coasts of Estonia have not been adequately determined. The main categories of available data are visual wave estimates made at a few coastal observation sites of the Estonian Hydrological and Meteorological Institute and from the quays of Tallinn harbour, and older wave atlases $\left[{ }^{1}\right]$. A relatively well studied area is Tallinn Bay $\left[^{2}\right]$ but this knowledge is limited to the summer season. Various wave models used for both scientific and engineering purposes $\left[{ }^{3-5}\right]$ have never been verified against measured data in Estonian coastal waters.

Lately, detailed information about the natural wave regime in a specific coastal area of Estonia was urgently needed as a basic information in the framework of studies of the wakes of fast ferries $\left.{ }^{6}\right]$. Ship-generated waves have become an environmental problem of growing concern in restricted waters and estuaries during the last years. In particular, in Scandinavia and in the United Kingdom, detailed studies of various aspects of fast ferry operation, including properties of their wakes, have been carried out already in the middle of $1990 \mathrm{~s}$ $\left.{ }^{7-10}\right]$. Recently, analogous studies have been performed (or are in progress) in many countries $\left[{ }^{11-17}\right]$.

Fast ferries produce fundamentally different wave systems as compared to conventional ships when sailing at supercritical speeds $\left[{ }^{18,19}\right]$. These waves, in particular at open sea, are relatively small in terms of wave amplitude compared to storm waves, but at times they have a very long wave period $\left[^{8,9,11,17}\right]$. While frequently hardly visible in deep water like tsunamis, they have occasionally been found to cause violent impacts on the coast and energetic plunging breakers on beaches $\left[{ }^{8,9,20}\right]$. Wind waves and wakes of conventional ships, possibly having a larger amplitude in deep water but frequently clearly shorter wavelengths, in particular in specific estuarine areas $\left[{ }^{6}\right]$, undergo a much smaller amplification in the shallow coastal zone.

Strictly speaking, a ship passing through water surface produces a series of surface disturbances that are limited in both space and time, and are called ship wake. Formally, the structure of a wake can be examined with the use of the Fourier analysis. This technique allows to identify different wave components of the wake. Doing so is not always justified because a ship wake is a system of transient waves occasionally containing even solitary waves $\left[{ }^{18,19}\right]$. Yet the Fourier analysis apparently is applicable in areas remote from the ship track where the wake consists of many wave crests. For simplicity, below the shipgenerated water surface disturbances will be mostly called ship waves.

The influence of ship waves may be critical for certain processes in semienclosed estuaries or in areas usually not exposed to swell or severe local seas $\left[{ }^{21}\right]$. Tallinn Bay is an example of a relatively well sheltered sea region with particularly heavy fast ferry traffic (Fig. 1). Nearly 70 crossings of the bay take place daily during the high season. A variety of different types of high-speed ships operate there (Table 1). Among them, one monohull vessel and four wavepiercing catamarans are capable of carrying cars and may be called fast ferries. 

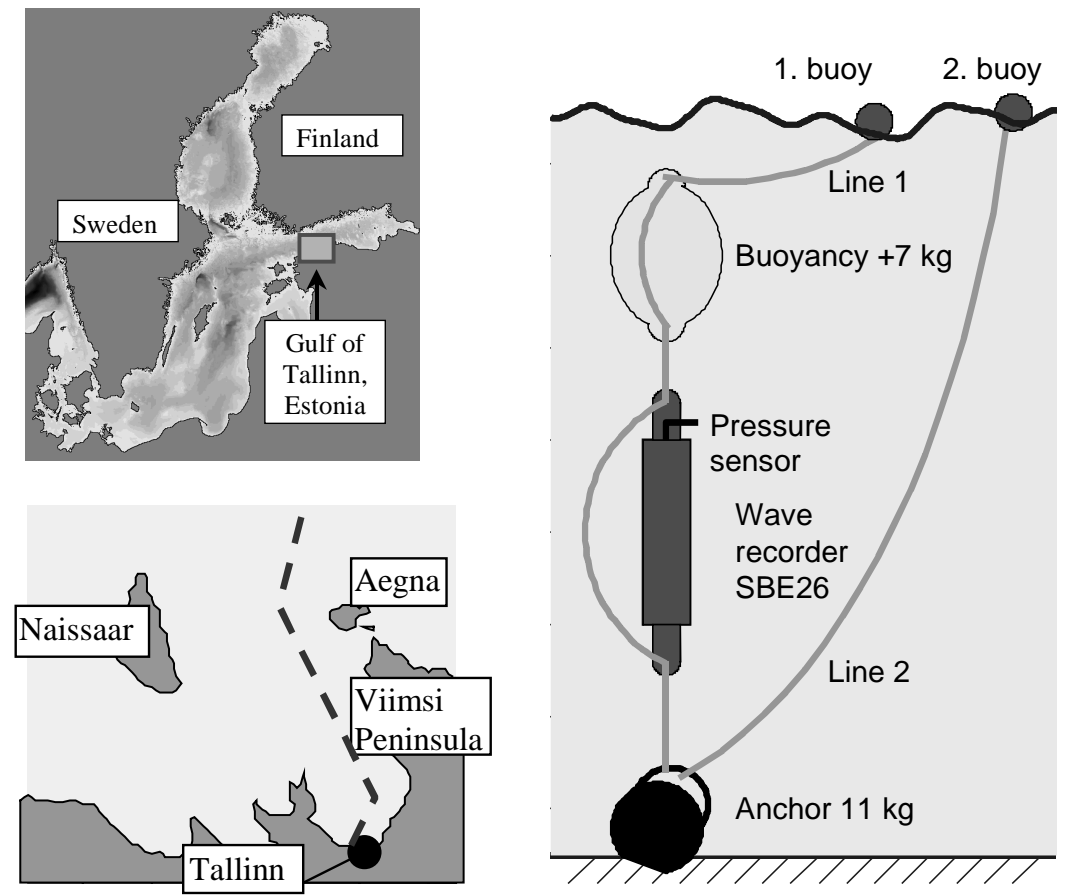

Fig. 1. Tallinn Bay and the Tallinn-Helsinki ship lane (the dashed line at the lower left panel) and the mounting scheme of the wave recorder (right panel).

Table 1. High-speed ships operating in Tallinn Bay in 2001-2002

\begin{tabular}{l|c|c|c|c|c|c|c}
\hline \multicolumn{1}{c}{ Name of the ship } & Type & $\begin{array}{c}\text { Length, } \\
\mathrm{m}\end{array}$ & $\begin{array}{c}\text { Width, } \\
\mathrm{m}\end{array}$ & $\begin{array}{c}\text { Draught, } \\
\mathrm{m}\end{array}$ & $\begin{array}{c}\text { Displace- } \\
\text { ment } \\
\text { light, } \mathrm{t}\end{array}$ & $\begin{array}{c}\text { Displace- } \\
\text { ment } \\
\text { loaded, } \mathrm{t}\end{array}$ & $\begin{array}{c}\text { Cruise/ } \\
\text { maximum } \\
\text { speed, knots }\end{array}$ \\
\hline SuperSeaCat IV & monohull & 100.3 & 17.1 & 2.6 & 900 & 1296 & $38 / 42$ \\
Tallink AutoExpress & catamaran & 79.95 & 23 & $2.60-3.43$ & 881 & 1182 & $35 / *$ \\
Tallink AutoExpress 2 & catamaran & 82.3 & 23 & $2.79-3.50$ & 886 & 1247 & $38 / *$ \\
Baltic Jet & catamaran & 60 & 16.5 & 2.22 & 515 & 635 & $36 / 38$ \\
Nordic Jet & catamaran & 60 & 16.5 & 2.22 & 515 & 635 & $36 / 38$ \\
Jaanika and Laura & hydrofoil & 37.5 & 8.4 & $1.4-4.6$ & 105 & 130 & $37 / 37$ \\
Linda Express & hydrofoil & 37.3 & 12.4 & $0.93-3.5$ & 125 & 175 & $52 / 55$ \\
(wakes not recorded) & catamaran & & & & & &
\end{tabular}

* No data available

This paper describes a part of the results of an extensive field study of both wind wave and ship wave properties in different parts of the coastal area of Tallinn Bay. The main goal was to identify the typical and extreme parameters of wakes of different types of ships and to describe their energetic properties in different coastal areas of the bay. For that reason, nearly 1000 ship wakes were traced during about 200 hours on 15 days. In the current paper, only properties of wakes necessary for estimates of the bulk influence of ship waves on coastal 
processes of Tallinn Bay are discussed. Many other important questions, for example, the dependence of the properties of particular wakes on the navigation details (vessel speed, distance from the ship track, ship load, and vessel trim), are not considered.

The study of the recordings comprised an analysis of the raw pressure signal, spectrally filtered pressure signal, water surface time series (reconstructed on the basis of the Fast Fourier Transform [FFT] method) and spectral properties of the wave field. The estimates of the relative role of ship waves (based on both the experimental data and numerically estimated natural wave) climate and a comparison of the influence of waves of different origin are described in $\left[{ }^{22}\right]$.

In Section 2, the measurement technique and sites are described. An overview of actually measured wind wave properties in different wind conditions and the general features of natural wave fields (partially based on the older observations) during the relatively calm spring and summer season is given in Section 3. The structure of wake patterns of different ships is analysed in Section 4. The maximum and mean values as well as the spatial variability of the wake heights of fast ferries are described in Section 5. As a new development in the ship wave analysis, daily average frequency spectra of wakes are constructed and discussed in Section 6. Based on these distributions, the average ship wave energy density and its flux (equivalent to the wave-induced power density) are calculated for different parts of the coast. These distributions and quantities allow to judge which component of the ship wake affects a particular site.

\section{MEASUREMENT TECHNIQUES}

There exists a large number of various devices to measure wave characteristics. The method and apparatus have to meet several criteria: the device has to be selfpowering, usable in a remote area, mobile and fairly easy to be placed and positioned correctly. It must be able to represent adequately both wind and shipgenerated waves, to cope with extreme waves, and, last but not least, to fit into the budget. The periods of waves generated by fast ferries may vary from 3 up to $40 \mathrm{~s}\left[{ }^{9,21}\right]$, thus pressure sensors can be used for adequate description of their basic parameters. The pressure data well represents wave periods and heights but not necessarily the exact water surface time series and the wave profile. As for wind waves, this technique only allows to estimate the one-dimensional wave spectrum. Its another shortage is that it fails to register short waves, because pressure fluctuations caused by short waves decay fast with the increase of the depth.

Several witnesses claimed that ship wave heights have been as large as $4 \mathrm{~m}$ in specific sites of Tallinn Bay. The visual estimates of wake patterns by experienced personnel and a series of preliminary experiments in 2001 (with the use of the pressure sensor SD204, SAIV Ltd., Norway) showed that the wave heights at the depths of 7-10 $\mathrm{m}$ did not exceed $2 \mathrm{~m}$ and generally were less than $1 \mathrm{~m}\left[{ }^{13}\right]$. Yet the actual possibility of occurring of up to $2 \mathrm{~m}$ high waves (see below) suggested that the wave properties should be measured at somewhat 
larger depths than $3 \mathrm{~m}$, used as the reference depth for the wake height criterion in Denmark and New Zealand $\left.{ }^{8,21}\right]$. The reason is that particularly high shipgenerated waves may already be in the breaking stage at small depths. Their shape may be quite far from the sinusoidal one and, as a result, their heights may be severely underestimated from the pressure time series.

During the field experiments in 2002, the wave properties were measured in areas with the depth of about $5 \mathrm{~m}$ (6.7 m on 14.04.2002 near Aegna jetty) in different parts of Tallinn Bay and at different distances $(2-8 \mathrm{~km})$ from the ship lane (Table 2). The measurement sites were chosen near the coastal areas that apparently were the most vulnerable ones with respect to the ship waves (see the map on the inside back cover and $\left.\left[{ }^{22,23}\right]\right)$.

Wave recorder SBE26 (Sea-Bird Electronic), based on the pressure sensor with a traditional mounting scheme, was used (Fig. 1). The sensor was positioned at the depth of 2-2.5 m (on 14.04.2002 at about 3.5 m near Aegna jetty) in order to adequately represent even the largest waves (Table 2). This measurement depth allowed to trace wave components with the periods $>1.5 \mathrm{~s}(>2 \mathrm{~s}$ on 14.04.2002). This resolution is suitable for wind wave measurements in the case of moderate and strong winds when wave energy is mostly concentrated in components with larger periods.

The minimum length of a measurement interval must for several times exceed the maximum period of recorded waves. Its maximum length is only limited by the memory of the wave recorder. However, longer time series often contain lowfrequency pressure disturbances caused by the changes of the local water depth and possibly by the variability of local currents. Various measurement intervals from 4 min $16 \mathrm{~s}$ to $34 \mathrm{~min} 8 \mathrm{~s}$ were used at different sites and sessions (Table 2). The longer intervals somewhat exceeded the frequently used measurement time (20 $\mathrm{min}$ ) in wind wave measurements.

The sampling frequency was $4 \mathrm{~Hz}$, thus, each record contained from 1024 to 8192 pressure snapshots. Individual records were separated by a pause (specific to the device in use) with a duration from 30 to $76 \mathrm{~s}$. During the pause, the device established the mean water level. The record length and the duration of the pause were fixed during each measurement day.

The analysis of the pressure data in each record follows the classical procedure of determining surface wave properties from the pressure time series in contemporary devices $\left[{ }^{24}\right]$. The pressure data for each record is first de-meaned and de-trended and then converted from psi to pascals. The mean is used for calculating the instrument depth. Next a Hanning window is applied to suppress the spectral leakage that occurs when the data contains a periodic signal with a frequency that does not coincide with any of the exact frequencies of the FFT for a particular record. The windowing operation reduces the total energy represented by a record, thus each of its elements is multiplied by a proper scale factor.

Further, the FFT of a record (with the number of points equal to the number of pressure snapshots in the record) is performed to obtain the amplitude and phase information of wave components with the frequencies of the FFT. To prevent 


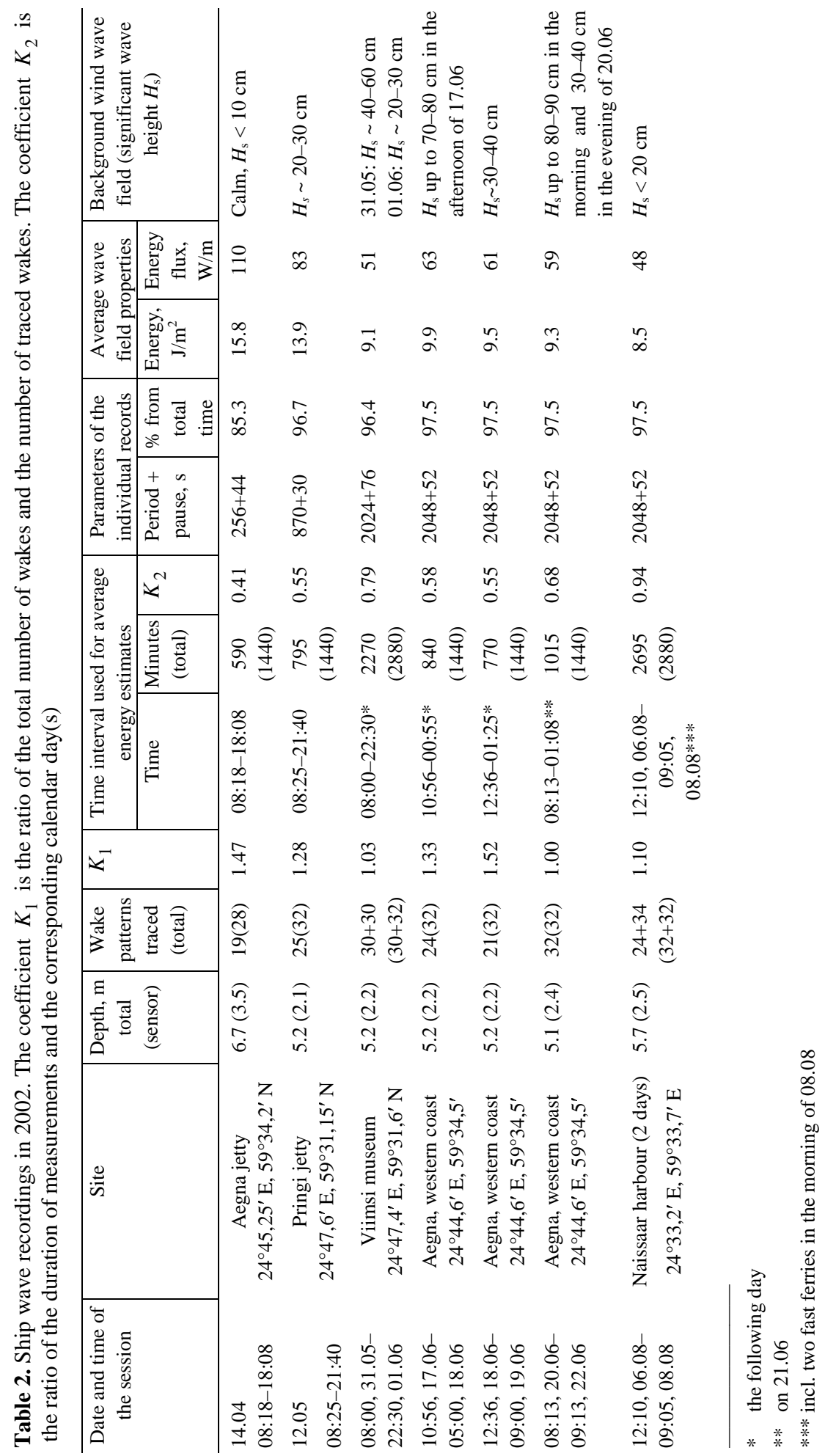


noise in the pressure time series from being mapped into unrealistic short wave heights, the amplitudes of waves with frequencies exceeding a certain threshold are set to zero. For the device and sampling frequency in use, the threshold is defined as a frequency for which the measured pressure is 100 times less than the pressure at the surface level. Next, the spectral density of the pressure is obtained from the pressure wave amplitude information and converted to the spectral density of the surface wave energy (below called wave spectrum) with the use of the attenuation rates of the subsurface pressure for the given instrument position, water depth, and wavelength.

To obtain the estimates of water surface time series, these attenuation rates are first multiplied by the properly scaled results of the FFT of the pressure series. The inverse FFT is then taken from the resulting spectral estimates of surface wave amplitudes. Next, the inverse of the Hanning window is used in order to eliminate the influence of the windowing operation applied to the pressure time series. The procedure fails near the end points of the pressure record where the surface fluctuations are simply set to zero. Finally, each element of the resulting time series is multiplied by a proper scaling factor to compensate the influence of the inverse Hanning window.

Wind wave fields are characterized by the significant wave height $H_{\mathrm{s}}$ (the mean height of one third of the highest waves), directly obtainable from the wave spectrum. This measure obviously is not applicable for ship wakes, in particular for their long-wave parts that are transient waves. For that reason, a completely different approach was used to estimate their height. A de-meaned and detrended pressure record was filtered with the use of a low-pass filter with the cutoff frequency of $0.2 \mathrm{~Hz}$ (equivalently, waves with periods $<5 \mathrm{~s}$ were excluded). The resulting pressure time series contained a very small amount of wind waves. The height of the long-wave disturbances was then estimated individually for each single wave with the use of the classical zero-upcrossing method $\left[{ }^{25}\right]$. The wave period was estimated as the time interval between subsequent pressure zero-crossings. The pressure attenuation rate for the particular wave period and the instrument and water depth is applied by converting the pressure data to the wave height. Doing so implicitly presumes that a sinusoidal wave with the period as defined above contains all long-wave energy within such an interval. However, an error caused by this assumption is relatively small because the attenuation rate varies insignificantly for the typical period range (8-12 s) of long ship waves in the real measurement conditions.

\section{PROPERTIES OF WIND WAVES IN DIFFERENT WIND CONDITIONS}

In order to perform a relevant comparison of wind waves and ship waves, the wind wave climate was modelled with the use of a high-resolution version of the WAM wave model $\left[^{6}\right]$. A number of wind wave properties, corresponding to 
different wind conditions, were estimated from in situ measurements. Additionally, existing historical wave data were analysed $\left[{ }^{2}\right]$.

Weak and moderate winds mostly dominated during the measurement campaign. The wave field properties corresponding to rough seas were recorded during a gale when the wind speed at open sea was $14-16 \mathrm{~m} / \mathrm{s}$ and the significant wave height at the western coast of the Island of Aegna was up to $2 \mathrm{~m}$. This storm was followed by an uncommonly strong swell with wave periods up to $8 \mathrm{~s}$.

The significant wave height did not exceed $20-25 \mathrm{~cm}$ in Tallinn Bay in weak wind conditions $(4-5 \mathrm{~m} / \mathrm{s})$. Since the dominating wave periods frequently were only $1-2 \mathrm{~s}$, the measurement procedure was not appropriate for describing such wave fields.

Typical spectra of wave fields occurring in moderate wind conditions are presented in Fig. 2. During the preceding night, weak winds dominated in the whole Gulf of Finland, a swell was absent and the wave height was $10-15 \mathrm{~cm}$. About at 10:00 the onshore wind speed increased up to 5-6 m/s. At noon, the wind speed increased to $7-8 \mathrm{~m} / \mathrm{s}$ for several hours. The significant wave height increased up to 50-60 cm within three hours after noon and remained practically constant until the late evening, although the wind speed was somewhat higher during a couple of hours. The dominating wave period was $2-3 \mathrm{~s}(0.33-0.5 \mathrm{~Hz})$ until the saturation of the wave heights (Fig. 2a). Further on, the portion of waves with periods 3-4 s increased considerably but the mean period still remained equal to $3-3.5 \mathrm{~s}$ (about $0.3 \mathrm{~Hz}$ ).

If onshore wind is stronger, the wave heights increase and a swell becomes noticeable after a while. Figure $2 \mathrm{~b}$ describes the structure of the wave field that occurs when an initial moderate wind of $6-8 \mathrm{~m} / \mathrm{s}$ is replaced by a stronger wind $8-11 \mathrm{~m} / \mathrm{s}$ during several hours. Similar wind conditions covered the whole western part of the Gulf of Finland and a swell with periods about $6 \mathrm{~s}$ formed an
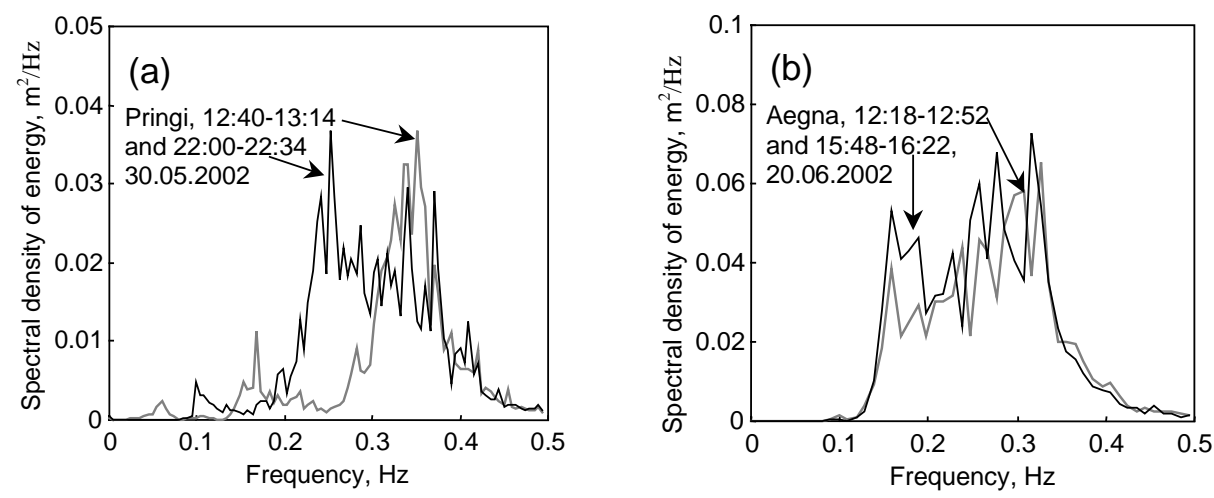

Fig. 2. (a) Spectral density of wave energy in Tallinn Bay in the initial phase (grey line, $H_{\mathrm{s}}=52 \mathrm{~cm}$ ) and after spectral saturation (solid line, $H_{\mathrm{s}}=54 \mathrm{~cm}$ ) during a moderate wind event $(6-8 \mathrm{~m} / \mathrm{s})$. The small peaks for waves with the frequency $\leq 0.15 \mathrm{~Hz}$ are caused by fast ferries. (b) Spectral density of wave energy at $3 \mathrm{~h}$ (grey line, $H_{\mathrm{s}}=89 \mathrm{~cm}$ ) and $6 \mathrm{~h}$ (solid line, $H_{\mathrm{s}}=87 \mathrm{~cm}$ ) after an increase of the wind speed from $6-8 \mathrm{~m} / \mathrm{s}$ to $9-11 \mathrm{~m} / \mathrm{s}$. 
essential part of the wave field. After an increase of the wind speed, the wave height increased from 70 to $90 \mathrm{~cm}$. Initially, the energy was mostly concentrated in wave components with periods about 3-3.5 s. Only several hours later waves with periods exceeding $4 \mathrm{~s}$ started to grow. The resulting saturated wave field had a wide spectrum with more or less uniform energy distribution between waves with periods about $3-6 \mathrm{~s}(0.16-0.3 \mathrm{~Hz})$. This is consistent with the observation in $\left.{ }^{26}\right]$ suggesting that either wide or double peaked wave spectra frequently occur in the Baltic Sea.

A wave record made during a west gale that began at noon on 21.06 with wind speeds about $15 \mathrm{~m} / \mathrm{s}$ and contained winds up to $18 \mathrm{~m} / \mathrm{s}$ serves as an example of the wave field during relatively strong storms. Since weak winds $(4-5 \mathrm{~m} / \mathrm{s})$ preceded the gale, a swell was practically absent and young waves with periods about $2.8 \pm 0.5 \mathrm{~s}$ (about $0.4 \mathrm{~Hz}$ ) dominated during the first three hours of the gale (Fig. 3a). The wave height reached $90 \mathrm{~cm}$ at 14:00. During the subsequent two hours the wave height was doubled. Such a rapid growth of the wave height occurred because the wind speed rapidly increased and, simultaneously, the wind direction turned to the west. At the storm maximum (about 5-6 h from the beginning of the gale) the wind speed reached $18 \mathrm{~m} / \mathrm{s}$ (Fig. 3b). A substantial part of the wave energy was transferred to waves with periods $4.3 \pm 0.5 \mathrm{~s}$ (about $0.2-0.25 \mathrm{~Hz}$ ) and the wave spectrum obtained the classical JONSWAP shape $\left[{ }^{27}\right]$. Until this time instant, wind waves dominated the sea state and swell was insignificant. Further on, the wind speed decreased a little (to $12-14 \mathrm{~m} / \mathrm{s}$ ) and the direction remained WSW until midnight. The wave height was close to $2 \mathrm{~m}$ during four hours until about 21:30 and reached the 1-year return value according to $\left[{ }^{6}\right]$. During this phase of the storm, the wave spectrum widened towards longer waves and the spectral maximum was shifted to the
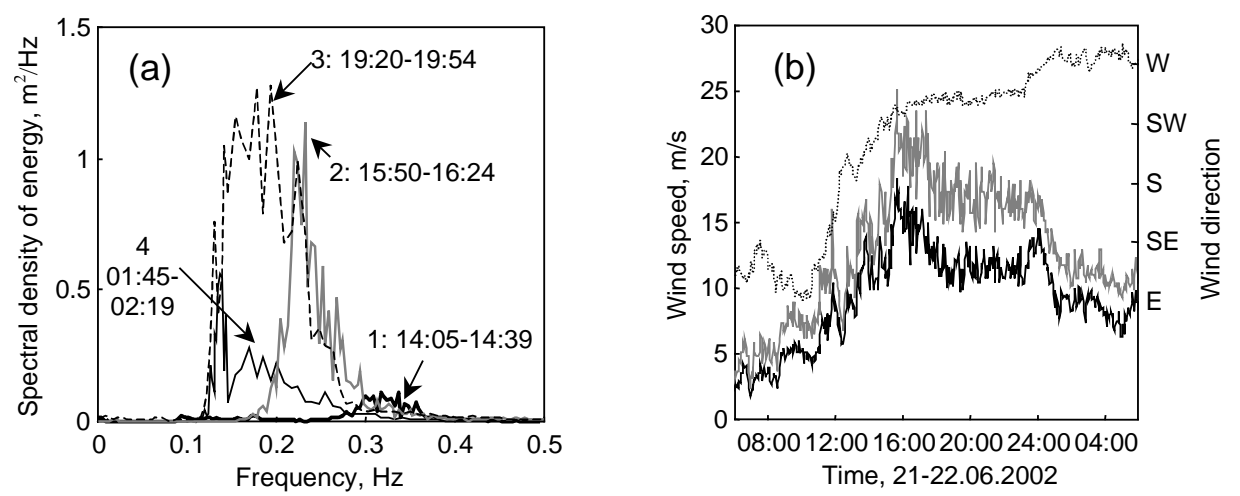

Fig. 3. (a) Spectral density of wave energy near the western coast of Aegna during different stages of a strong gale on 21-22.06: 1 - at the initial stage of the wave storm, young waves, $H_{\mathrm{s}}=95 \mathrm{~cm}$; 2 - at the time instant when the maximum wind speed of the gale occurred, $H_{\mathrm{s}}=186 \mathrm{~cm}$, young waves; 3 - at the time instant when the maximum significant wave height of the gale was reached, mixed seas, $H_{\mathrm{s}}=194 \mathrm{~cm}$; 4 - the final stage of the storm, swell-dominated seas. (b) Wind speed (solid line), wind speed in gusts (grey line), and wind direction (dotted line) at Miiduranna harbour on 21-22.06. 
periods $5-6 \mathrm{~s}$ (about $0.16-0.2 \mathrm{~Hz}$ ). By midnight, the significant wave height decreased to $150-160 \mathrm{~cm}$. In the final stage of the storm, the wind speed decreased to $10 \mathrm{~m} / \mathrm{s}$, the wave height was about $1 \mathrm{~m}$ and an intense swell with periods $7.5-7.7 \mathrm{~s}$ (about $0.13 \mathrm{~Hz}$ ) dominated the wave field (Fig. 3a). So large swell periods are extremely seldom $\left[{ }^{2}\right]$ and suggest that this storm had a relatively long duration and covered a large sea area.

The measured wave field properties well coincide with the ones predicted by a high-resolution version of the WAM model for moderate and strong wind conditions $\left[{ }^{13}\right]$ as well as with the results of older experimental data for the summer season $\left[^{2}\right]$. Based on the measurement campaign in 2002, calculated wave statistics $\left[{ }^{6}\right]$ and data in $\left[^{2}\right]$, the wave field properties in Tallinn Bay during the relatively calm spring and summer season can be summarized as follows.

Young wind waves mostly dominate in the wave field during this season. The significant wave height $H_{\mathrm{s}}$ does not exceed $25 \mathrm{~cm}$ in weak wind conditions $(\leq 5 \mathrm{~m} / \mathrm{s})$ whereas the typical wave periods are 1-2 s. In moderate wind conditions $(6-8 \mathrm{~m} / \mathrm{s})$ wave height is about $50-60 \mathrm{~cm}$ and is reached within a couple of hours. The mean wave periods vary from $2-3 \mathrm{~s}$ to $3-4 \mathrm{~s}$ depending on the duration of the wind. If moderate wind blows many hours, a significant swell component with the period about $4 \mathrm{~s}$ typically appears in the wave field.

The winds about $10 \mathrm{~m} / \mathrm{s}$ excite wave fields with the wave height up to $1 \mathrm{~m}$, depending on the site, wind direction, and duration. At these wind speeds, a mixed wave regime consisting of young wind waves with a frequency about $3 \mathrm{~s}$ and a swell with a frequency of $4-5 \mathrm{~s}$ is typical. Gales with the wind speed about $15 \mathrm{~m} / \mathrm{s}$ excite the wave height about $2 \mathrm{~m}$. The dominating wave period may largely vary depending on the duration of the gale but high waves with periods $>5 \mathrm{~s}$ appear infrequently. Swell-dominated seas are relatively infrequent and normally appear after strong storms.

This description suggests that the dominating wave periods during the spring and summer seasons normally are a few seconds and reach 5-6 s only in exceptional cases in the area in question (although the significant wave height may reach the 1-year return value). However, the properties of wave fields during the windy autumn and winter seasons may considerably differ from the described one.

\section{MAIN PROPERTIES OF THE WAKE PATTERNS}

When a ship passes through the water surface, it produces a wake - a series of waves. The basic properties of the wave pattern have been known for a long time (see, for example, $\left[{ }^{18}\right]$ and bibliography therein). Two sets of divergent waves move forward and out from the sailing line, and one set of transverse waves moves in the direction of the ship. The properties of the pattern strongly depend on the depth Froude number $F_{h}=V / \sqrt{g H}$, where $V$ is the ship speed, $g$ is the gravity acceleration and $H$ is the water depth. The wave heights increase rapidly if $F_{h} \rightarrow 1$ (called high-speed subcritical regime). At a specific (critical) speed, a single large bow wave may emerge with its crest normal to the sailing line. 
Beyond this speed (in supercritical regime) the wave amplitudes decrease with increasing Froude number for a certain bounded range of $F_{h}$.

The passenger ships operating in Tallinn Bay have greatly different wake properties. Although the hydrofoils Jaanika, Laura, and Linda Express (Table 1) are capable of sailing at supercritical speeds, the height of their wake generally does not exceed $10 \mathrm{~cm}$ in the coastal area of the bay whereas the wave periods were 3-4 s. The wake of Jaanika and Laura is practically indistinguishable from the natural background even in calm days. It only becomes evident in the neighbourhood of Katariina jetty that lies in the proximity of the route of the hydrofoils $\left[{ }^{13}\right]$.

The conventional ferries (Vana Tallinn, Fantaasia, Nordlandia, Meloodia, Romantika) sail at moderate depth Froude numbers $\left(F_{h} \leq 0.5\right)$. They excite waves that have typical heights of $20-30 \mathrm{~cm}$ and a maximum height of $40 \mathrm{~cm}$ in the eastern coastal zone of Tallinn Bay (i.e., at a distance of about $2 \mathrm{~km}$ from the ship lane). The typical wave periods are 3-4.5 s. The waves are not distinguishable from the natural wave background near the western coast of the bay (where only the wake of Regina Baltica operating on Tallinn-Stockholm line was distinguishable).

The fast ferries (high-speed catamarans Nordic Jet, Baltic Jet, AutoExpress, AutoExpress 2, and the monohull vessel SuperSeaCat IV, Table 1) may operate at speeds near to or exceeding the critical speed. The height of their wake frequently exceeded $1 \mathrm{~m}$ whereas the periods of the highest wave components were 10-15 s. Below we shall consider mostly waves generated by these ships. Frequently it was not possible to distinguish the wakes of similar ships from each other. For that reason, below we use the double names Nordic/Baltic Jet and AutoExpress/2. Finnjet has a lengthened hull similar to that of the conventional ferries. Powered by gas turbines, she is capable to sail as rapidly as fast ferries. However, she normally sailed at moderate depth Froude numbers and generated waves with moderate heights and periods.

Technically, the fast ferries may sail in the transcritical velocity range $\sqrt{g H} \pm 15 \%$ between Tallinn passenger harbour and Aegna jetty $\left[{ }^{22}\right]$. The resulting wave system disperses slowly and may remain more or less coherent for a long time. For ships sailing southwards, the large bow wave, possibly generated at the near-critical speeds, apparently disturbs the area from Katariina jetty to Pirita (see detailed map of Tallinn Bay on the inside back cover of this issue). In specific cases, this wave may reach also Pringi jetty or Miiduranna harbour. If a ship sails towards Helsinki, the large wave may hit the SW coast of Aegna. The other locations of the coastal zone of Tallinn Bay are mostly affected by divergent waves. The coastal zone of the Island of Naissaar lies at about $8 \mathrm{~km}$ from the ship lane. A hit of this area by a large bow wave generated in the transcritical regime is not probable.

The wake of a fast ferry operating at high speeds (both in sub- and supercritical regime) typically consisted of two or three wave groups (Fig. 4). It arrived about 5-10 min after the ship had passed, lasted about ten minutes and 
consisted of several tens of waves (cf. $\left[^{7-9,20,21}\right]$ ). The first group consisted of waves with periods of 15-9 s (the long waves arriving first) and had a duration of 3-4 min. The second group arrived a few minutes after the first one, consisted of waves with periods $9-7 \mathrm{~s}$ and had a duration of 4-5 min. The waves of the groups had distinctly different periods (Fig. 5a). As different from the analysis in $\left[{ }^{9}\right]$, we did not distinguish an underlying swell wave, probably representing

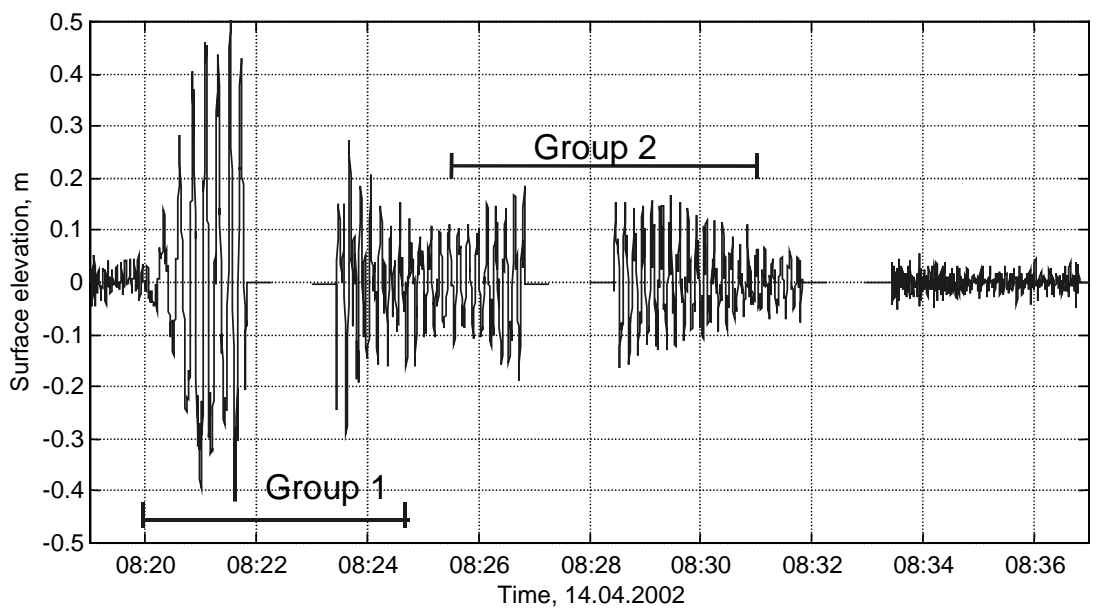

Fig. 4. Waves generated by Autoexpress/2 near Aegna jetty.
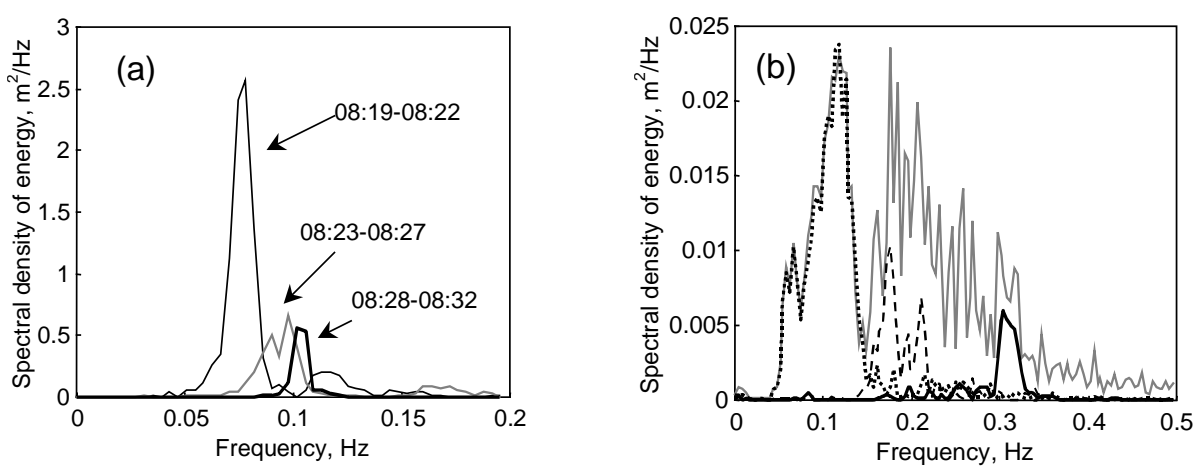

Fig. 5. (a) Spectral density of the energy of three parts of the wake of Autoexpress $/ 2$ from Fig. 4. The highest waves leading the wake had periods of $13-14 \mathrm{~s}$ and the final part - about $9 \mathrm{~s}$. The spectrum of waves at 08:33-08:39 represents the natural wave background and is not distinguishable in the scale of the figure. (b) Spectral density of the energy of three wake pattern components of SuperSeaCat IV near the western coast of Aegna at 00:05-00:39 on 21.06 (see Fig. 6). The dotted line represents the first wave group, the dashed line the second group and the bold line the third group. The grey line describes the spectrum of the whole wave field. The long wave components have the dominating periods about $16 \mathrm{~s}$ and $9-10 \mathrm{~s}$. The wake is superposed by a relatively intense mixed wave field with the significant wave height about $30-35 \mathrm{~cm}$ and the mean period about $4 \mathrm{~s}$. Although the group of short waves has a duration of only $1 \mathrm{~min}$ from the 34-min trace, it is still clearly visible in the wave spectrum as a double peak at the frequency of about $0.3 \mathrm{~Hz}$. 
transverse waves. Its height generally was much smaller than those of other groups and it was not always present.

The third wave group with a duration about one minute was recognized in a small number of recordings. It was repeatedly present in the wake of the SuperSeaCat but seldom in the wake of catamarans. It consisted of relatively short nearly monochromatic waves with periods of 3-4 s (Fig. 6) and was better identifiable in both the pressure time series and in the spectral representation than in the water surface time series (Fig. 5b). At times, it consisted of a superposition of two wave systems with slightly different periods. Owing to the monochromatic nature of this group, its components propagate together with a fixed speed and it may remain compact during a long time. Since it resembles an envelope soliton, the non-linear Schrödinger equation $\left[{ }^{28}\right]$ might be a proper tool for its analysis.

In the remote coastal zone of Naissaar the third group frequently contained the highest waves of the wake (see below). In the eastern part of the bay the waves of this group normally were smaller than the leading waves. A specific wake of SuperSeaCat IV was recorded at midnight of 18 June at the western coast of Aegna. The height of the long-wave part was about $60 \mathrm{~cm}$ but the shorter waves were about $90 \mathrm{~cm}$ high.

There were only a few cases when waves with periods exceeding $20 \mathrm{~s}$ occurred whereas their height did not exceed $10 \mathrm{~cm}$. Also, we did not register extensive water surface dropdown that frequently precedes the critical and supercritical wake $\left[{ }^{20,29}\right]$. The possible reason is that these waves generally appear when a ship sails in the transcritical regime during a longer time [ $\left.{ }^{9}\right]$. Notice that particularly long waves (with periods about $18-20 \mathrm{~s}$ or with a frequency about $0.05 \mathrm{~Hz}$, Fig. $5 b$ ) were frequently present simultaneously with the third wave group. Thus they both may characterize a specific sailing regime.

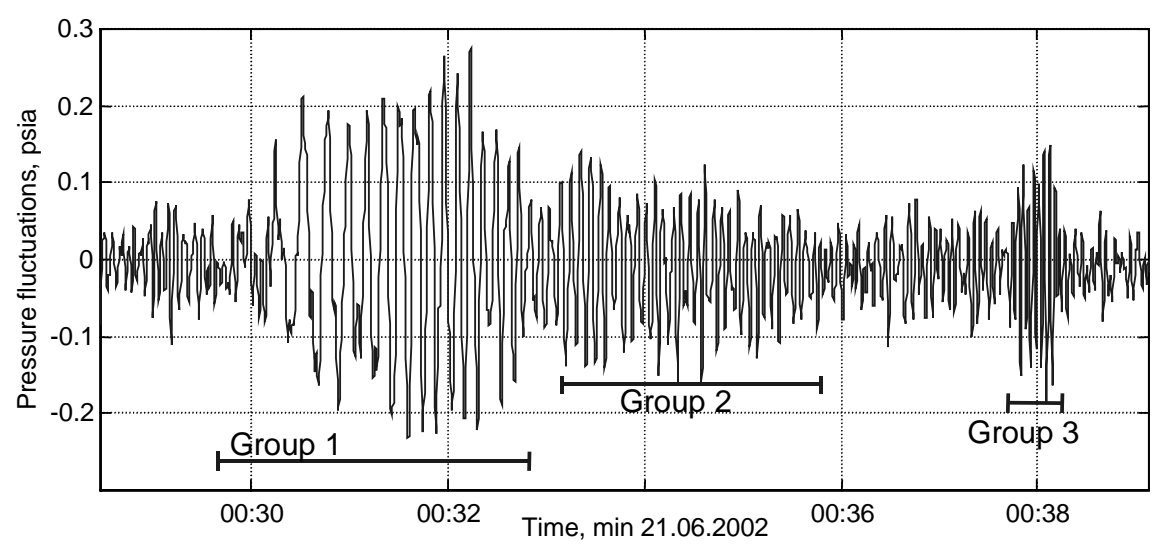

Fig. 6. Pressure fluctuations caused by the wake of SuperSeaCat IV near the western coast of Aegna. The first wave group has the maximum height of $45 \mathrm{~cm}$ and the second group of $25 \mathrm{~cm}$. The highest is the third group $(52 \mathrm{~cm})$. The significant height of the natural wave background is about $30 \mathrm{~cm}$. 
A peculiar wake of AutoExpress/2, sailing to Tallinn, was recorded in the late evening of 31 May near the Viimsi museum (Fig. 7). It consisted of eight crests with periods about $7.5 \mathrm{~s}$ and arrived about $11 \mathrm{~min}$ after the ship had passed. The duration of large waves was about one minute. The maximum height of the longwave component was about $80 \mathrm{~cm}$. This height was the maximum at this site. The maximum wave height derived from the analysis of the water surface time series (that includes also wind waves) was even $140 \mathrm{~cm}$.

A distinguishing feature of this wake was the asymmetry of the traced waves: the wave crests were higher than the troughs in both the pressure signal and the surface time series. Figure $7 \mathrm{~b}$ shows that there were no other distinguishable components in this wake pattern: the wave field properties during the rest of this record were identical to the those of the natural wave background during the next record. The described features suggest that this packet may be formed by a large bow wave generated when the ship was sailing in the near-critical regime.
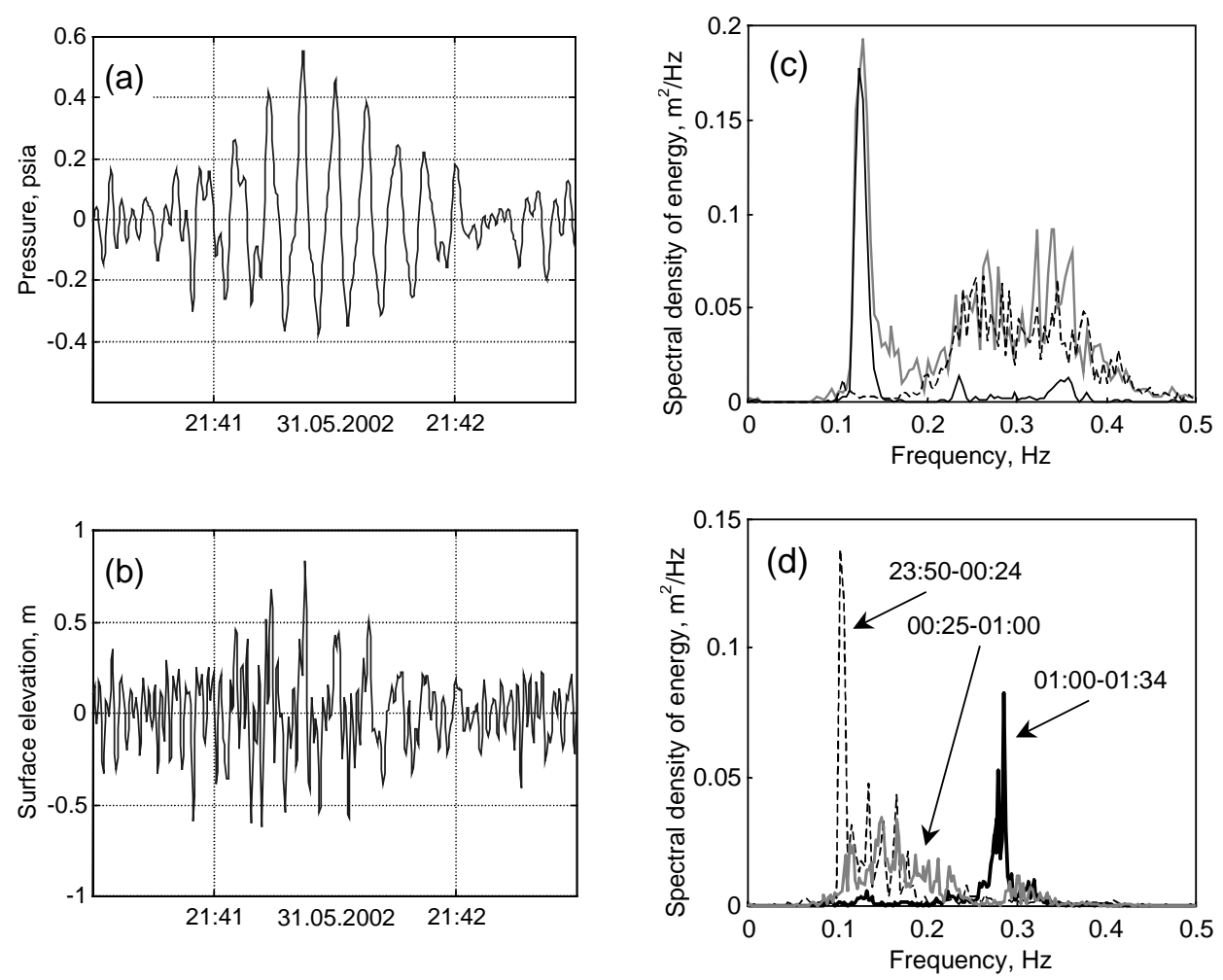

Fig. 7. (a) The wake of Autoexpress/2 sailing to Tallinn on 31.05 near the Viimsi museum in the pressure signal. (b) The corresponding surface time series. (c) Spectral density of the energy of the whole wave field at 21:25-21:49 on 31.05 (grey line), during two minutes of the intense waves at 21:40,5-21:42,5 (solid line) and during the following record at 21:50-22:24 (dashed line). (d) Spectral density of the energy of different parts of the wake pattern of SuperSeaCat (Fig. 8) near the coast of Naissaar 06.-07.08. 

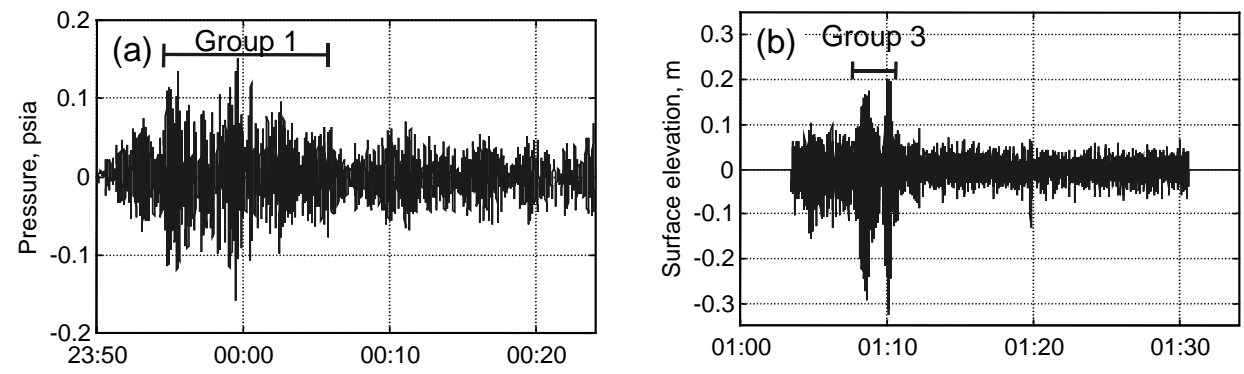

Fig. 8. (a) The leading part of the wake of SuperSeaCat IV near Naissaar harbour on 06.-07.08 in the filtered pressure signal (the wave components with periods $<5 \mathrm{~s}$ excluded); (b) the final part of this wake in the surface time series.

In the coastal zone of Naissaar, the duration of the group of the longest waves was typically $15-30 \mathrm{~min}$ owing to extensive dispersion. The duration of a wake pattern frequently exceeded one hour. The heights of individual waves were less than in the eastern part of the bay. However, the long waves were clearly identifiable in the spectral analysis. From three main parts of the wake, only the (optional) third group remained compact.

An example is the wake of SuperSeaCat sailing alone towards Helsinki at midnight (Fig. 8). The height of the waves from the first group (with duration about $10 \mathrm{~min}$ ) was about $18-20 \mathrm{~cm}$ and periods about $10-8 \mathrm{~s}$ (the longer waves arrived first). Its closing waves were the highest among the long wave components. The second group arrived after a pause of $15 \mathrm{~min}$, lasted about $15 \mathrm{~min}$, consisted of waves with periods about 5-6 s and heights about $15 \mathrm{~cm}$. The third group of short waves, with duration about $2 \mathrm{~min}$, arrived about one hour later than the leading waves. The heights of the waves from this group were comparable with those in the vicinity of the ship lane and reached $55-60 \mathrm{~cm}$.

\section{SHIP WAVE HEIGHTS AND PERIODS}

The measurement sites at the eastern coast of Tallinn Bay were located at a distance of 1.5-2 km from the ship lane, about 300-400 $\mathrm{m}$ from the coastal line in the vicinity of the $5 \mathrm{~m}$ isobath (see map on the inside back cover and Table 2). Thus it can be assumed that the differences of wake properties at the sites were caused either by the different location of the sites with respect to the sailing line or by possible differences in ship speeds. Below we mostly compare the heights of the long-period components of the wakes (with periods $>5 \mathrm{~s}$ ).

\subsection{Aegna Island}

The highest wake components produced by a single ship apparently occur at the southern coast of Aegna and near Aegna jetty (Fig. 9). The highest long wave of the whole campaign was recorded at 13:18 on 14.02.2002 in otherwise calm 


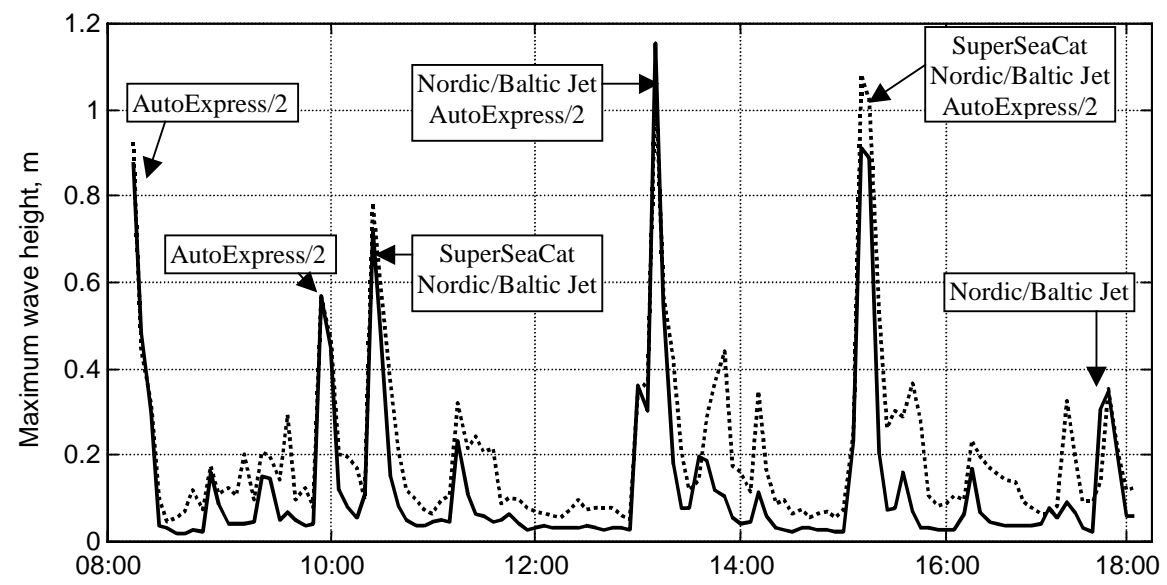

Fig. 9. The maximum height of the long wave components (periods $>5 \mathrm{~s}$ as suggested in $\left[{ }^{21}\right]$, bold line) and of the whole wake of fast ferries (dotted line) near Aegna jetty on 14.04. The temporal resolution is $5 \mathrm{~min}$. Shown are only ships sailing to Helsinki.

conditions $\left(H_{\mathrm{s}} \leq 8 \mathrm{~cm}\right)$, had the height of $108 \mathrm{~cm}$, the period of $11 \mathrm{~s}$, and was generated jointly by Nordic/Baltic Jet and AutoExpress/2 sailing to Helsinki.

Figure 9 shows a remarkable asymmetry of the height of long ship waves with respect to the sailing direction. From ten recorded traces of fast ferries sailing towards Helsinki, wave height twice exceeded $100 \mathrm{~cm}$ (once two ships and once three ships sailing more or less simultaneously), once it was about $90 \mathrm{~cm}$ (a single ship), and once about $80 \mathrm{~cm}$ (two ships). Only once the ship wake height was about $60 \mathrm{~cm}$ and once about $40 \mathrm{~cm}$. Thus $50 \%$ of ship passings were accompanied by waves higher than $1 \mathrm{~m}$ and $80 \%$ of the passings with wake height exceeding $80 \mathrm{~cm}$. A large part of energy of waves of ships sailing to Helsinki was concentrated in components with periods exceeding $10 \mathrm{~s}$ and occasionally reaching $15 \mathrm{~s}$.

The waves excited by ships sailing to Tallinn (in total 11 traces were recorded this day) were considerably smaller. The smallest wake of ships sailing to Helsinki is much higher than the highest one excited by ships proceeding to Tallinn. Their heights did not exceed $40 \mathrm{~cm}$ whereas the long wave components (with periods exceeding $5 \mathrm{~s}$ ) even did not exceed $20 \mathrm{~cm}$. This difference can be explained by the particular location of the site. It lies relatively close to the ship lane and is totally open to the southern direction. The highest tracked waves apparently were excited when ships sailed towards Helsinki occasionally with speeds close to the critical velocity. Since the site is sheltered from the NW direction, only divergent waves (that generally are lower than the single bow wave) from ships sailing to Tallinn reach this measurement site.

A large number of wake patterns was recorded at the western coast of Aegna during 17.-22.06 (Figs. 10 and 11). The maximum wave height was about $20 \%$ less than at the southern coast although the measurement site was closer to the ship lane and fully open to sea. The natural wave background was relatively 
intense in the afternoon of 17.06. The significant wave height was about $70-80 \mathrm{~cm}$ at 17:00-20:00. Also a swell with the height of about $20 \mathrm{~cm}$ and with the dominating period of about 4-5 s was present. Owing to so large heights and periods of wind waves during all sessions at this site, the shorter ship wave components were not identifiable from the record and only the long wave components with periods exceeding $5 \mathrm{~s}$ have been shown in Figs. 10 and 11. The maximum height of wind wave components with periods $>5 \mathrm{~s}$ was about $10 \mathrm{~cm}$. (This height can be roughly estimated from the position of the minima of the curve showing the long ship wave heights in Figs. 9-13.) Still the height of the long-wave part of the wakes can be easily distinguished from Fig. 10. Notice that the height of the ship waves is only weakly influenced by greatly different intensity of the wind wave field in two days. This feature suggests that interactions of the wind and ship waves generally do not significantly alter the ship wave height.

The natural wave background was less intense on 18 June when $H_{\mathrm{s}} \approx 20-30 \mathrm{~cm}$. The periods of long ship waves were, as above, relatively large $(9-13 \mathrm{~s})$ but their heights did not exceed $80 \mathrm{~cm}$. The heights of wind waves in this frequency domain varied from 5 to $20 \mathrm{~cm}$. SuperSeaCat IV excited the highest (about $60 \mathrm{~cm}$ ) long wave generated by a single ship.

The wave conditions on 20 June were comparable to those in the afternoon on 17 June: $H_{\mathrm{s}} \approx 100 \mathrm{~cm}$ at noon decreased to $H_{\mathrm{s}} \approx 30 \mathrm{~cm}$ by midnight. The highest long waves (the wave height $92 \mathrm{~cm}$ and the period about $10 \mathrm{~s}$, Fig. 11) were produced jointly by Nordic/Baltic Jet and AutoExpress/2, both sailing to Helsinki.

June 21 began with weak winds. The significant wave height was about $20-30 \mathrm{~cm}$ and the long wave components were practically absent. The heights of long ship waves did not exceed $65 \mathrm{~cm}$. At noon, a strong gale began. Starting

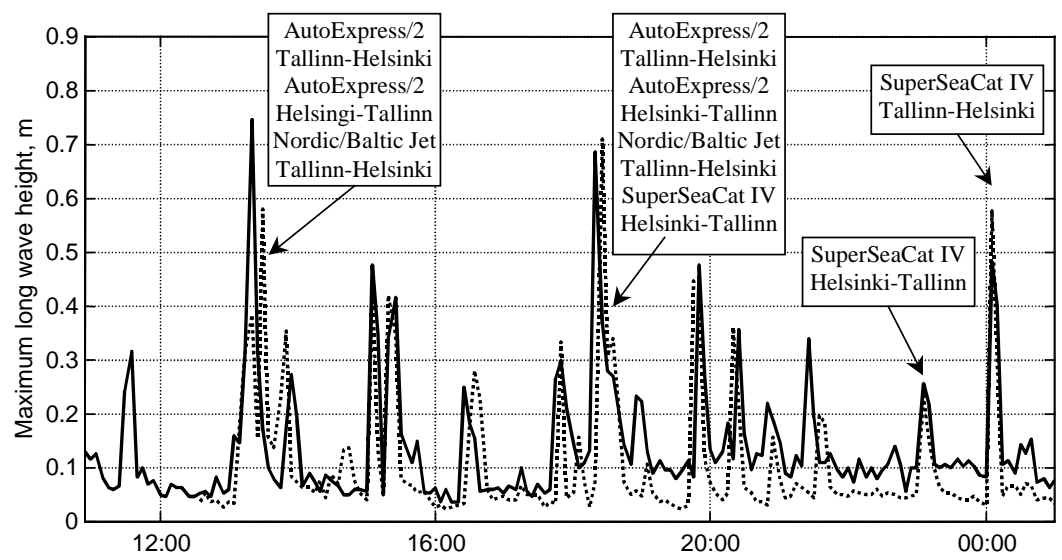

Fig. 10. The maximum heights of the long wave components (periods $>5 \mathrm{~s}$ ) near the western coast of Aegna on 17.06.2002 (solid line) and 18.06.2002 (dotted line). The temporal resolution is 5 min. Only ships generating the highest waves are indicated. 


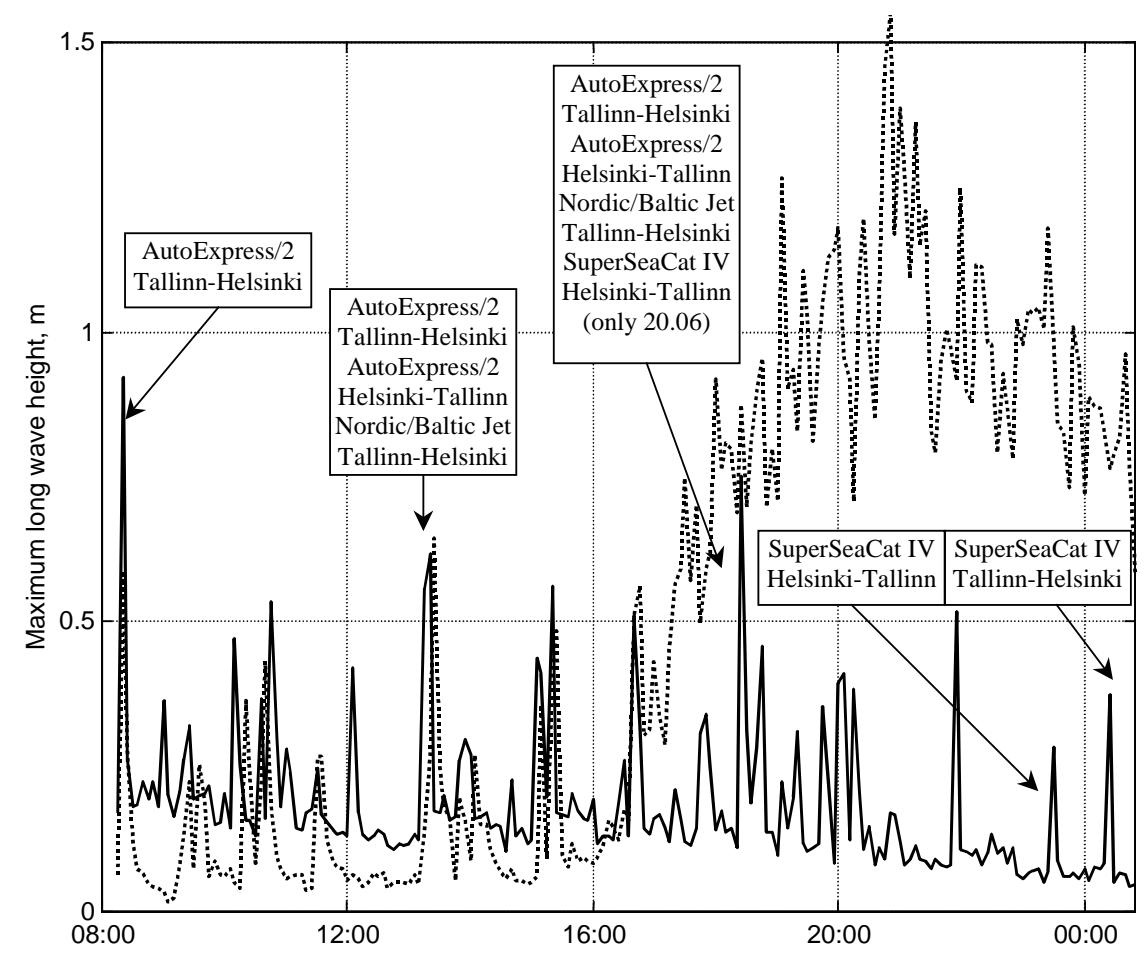

Fig. 11. The maximum heights of the long wave components (periods $>5 \mathrm{~s}$ ) near the western coast of Aegna on 20.06.2002 (solid line) and 21.06.2002 (dotted line). The temporal resolution is $5 \mathrm{~min}$. The fast ferry traffic was halted at about 18:00 on 21.06.

from about 16:00 relatively high wind wave components with periods 5-6 s were present in the wave field. It is remarkable that the heights of the long part of the wind wave field during a short time interval only a little exceeded the maximum heights of long ship waves. The asymmetry of wave heights with respect to the sailing direction was much smaller at this site than at the southern coast of Aegna (cf. Figs. 9 to 11 ).

Ship wakes optionally contained shorter waves of considerable height. Wave heights up to $1.5 \mathrm{~m}$ have been recorded several times. The highest waves $(2.3 \mathrm{~m})$ were tracked at 8:30 on 19 June near the western coast of Aegna about $10 \mathrm{~min}$ after AutoExpress/2 and Nordic/Baltic Jet had together sailed to Helsinki. Unfortunately, the leading waves of this pattern were not recorded. The highest waves apparently were formed as a superposition of wind waves with two ship wakes. The significant wave height of the natural background was about $50 \mathrm{~cm}$, thus the height of the ship-generated waves was, at least, $150 \mathrm{~cm}$. Apparently, they were not related to particularly high wave humps, theoretically occurring as a result of non-linear interactions of soliton-like single waves $\left[{ }^{13,30}\right]$. 


\subsection{Viimsi Peninsula}

The conditions for ship wave recordings were favourable during all the measurement sessions. The significant wave height was about $20-30 \mathrm{~cm}$ on 12.05 and 01.06 , and reached $40-60 \mathrm{~cm}$ on 31.05 . Generally, ship wave heights in the central part of the coast of the Viimsi Peninsula were somewhat less than near Aegna (Fig. 12). The maximum heights of long-wave components did not exceed $80 \mathrm{~cm}$. In a few cases (about $20 \%$ from the wake patterns) the wave height reached $60-70 \mathrm{~cm}$ but mostly they were about $40-50 \mathrm{~cm}$. The highest waves had periods about $6-8 \mathrm{~s}$ and were created by ships sailing to Tallinn. The asymmetry of wave heights with respect of the sailing directions was modest and the wake heights were relatively uniform.

The maximum wave height within three days at two different sites (located at $300 \mathrm{~m}$ from each other in otherwise identical conditions; together 85 tracked wake patterns) was about $175 \mathrm{~cm}$. This wave packet consisted of shorter waves formed as a superposition of waves generated by SuperSeaCat and Nordic/Baltic Jet proceeding to Helsinki. The role of wind waves was unessential, because significant wave height was only $15-20 \mathrm{~cm}$.

An interesting feature is that long-wave components were considerably higher on Saturday, 31 May than on Sunday, 1 June in otherwise identical conditions (Fig. 12). The timetable of the fast ferries on these days was identical, thus the changes in the wake character were apparently caused by variations in sailing conditions. This peculiarity suggests that the ships were sailing in a regime that was particularly sensitive with respect to small changes in the speed or trajectory.

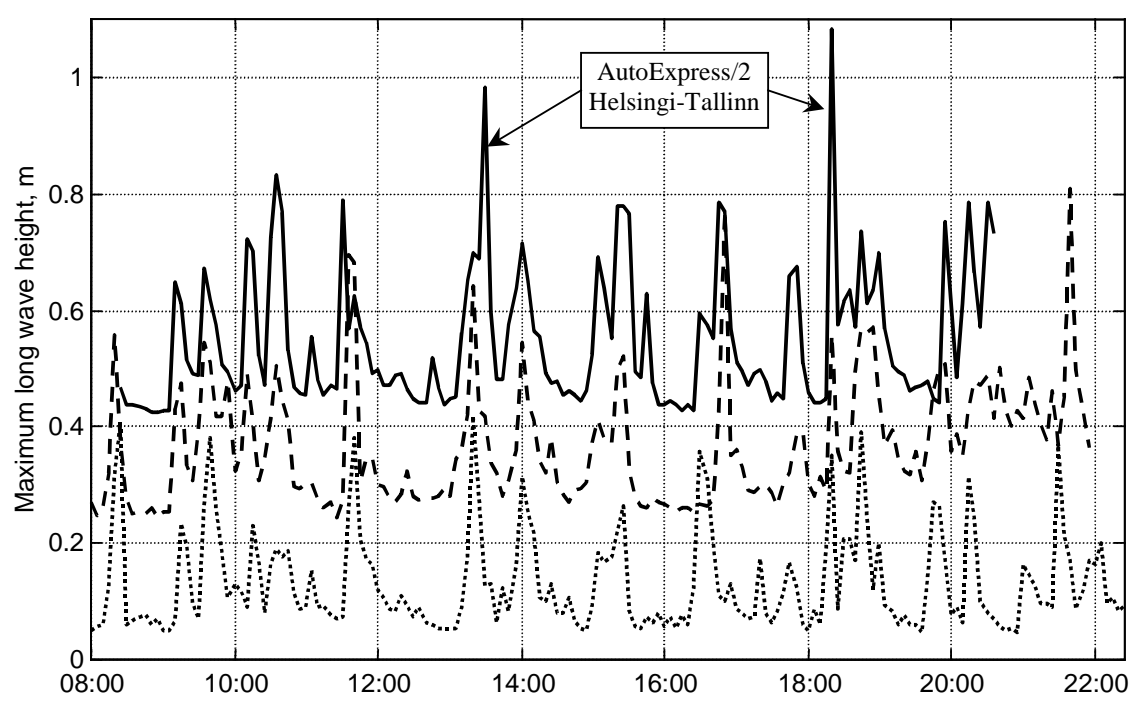

Fig. 12. The maximum heights of the long wave component (periods $>3 \mathrm{~s}$ ) near Pringi jetty 12.05 (solid line, shifted upwards by $0.4 \mathrm{~m}$ for better readability), at the Viimsi museum on 31.05 (dashed line, shifted upwards by $0.2 \mathrm{~m}$ ) and 01.06 (dotted line). The temporal resolution is $5 \mathrm{~min}$. 


\subsection{Naissaar Island}

The wind wave conditions were favourable for ship wave tracking. The significant wave height was $20-25 \mathrm{~cm}$ on 06.07 , decreased to a few $\mathrm{cm}$ in the early morning of 07.08 and was $10-15 \mathrm{~cm}$ during the rest of this day. The maximum height of the long-wave part of the wind wave background was about $5 \mathrm{~cm}$ on both days. However, for better comparisons with other sites only the maximum heights of long ship wave components are shown in Fig. 13. Typically, the heights and periods of long waves produced by fast ferries were $25 \mathrm{~cm}$ and 8-12 s, respectively. In individual cases, the long wave heights exceeded $30 \mathrm{~cm}$. The highest recorded long wave was close to $50 \mathrm{~cm}$ in the morning of 07.08.

As different from the wake properties near the Viimsi Peninsula and Aegna, the final groups of short waves with the periods of 3-3.5 s were frequently the highest near Naissaar. Their maximum height was about $70 \mathrm{~cm}$ and they reached $55-60 \mathrm{~cm}$ in three other cases within two measurement days.

Viscous dissipation of long ship waves along the way from the ship lane to the measurement site apparently does not cause such a strong decrease in wave amplitudes compared to those in the eastern part of the bay. The sea bottom between the ship lane and Naissaar has a variable bathymetry, thus energy dissipation owing to wave-bottom interaction damps longer waves to some extent. Comparison of Fig. 13 with Figs. 9-12 shows that the peaks in the long wave heights were generally wider (accordingly, the duration of long wave groups was larger) in the coastal zone of Naissaar compared to the other areas. This feature suggests that the decrease in wave amplitudes probably happened owing to the dispersive nature of wakes (that typically consisted of waves with different periods and, consequently, different propagation velocities).

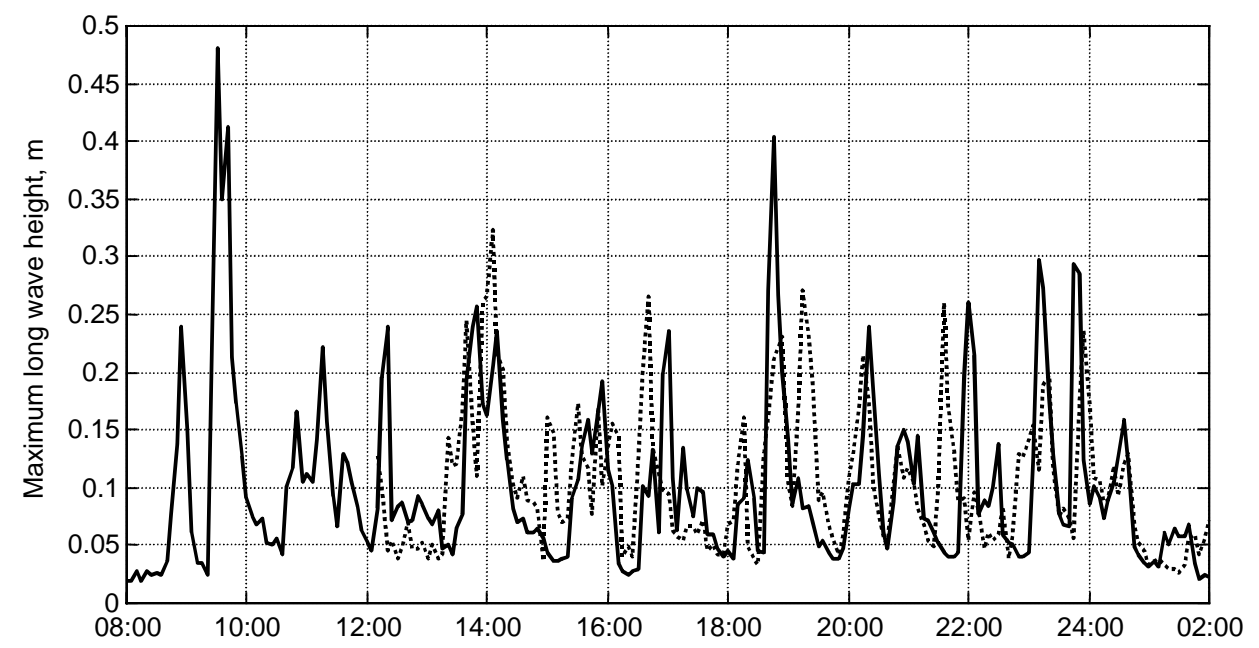

Fig. 13. The maximum heights of the long wave components (periods $>5 \mathrm{~s}$ ) near Naissaar harbour on 06.08 (dashed line) and 07.08 (solid line). The temporal resolution is $5 \mathrm{~min}$. 
Another interesting property of ship waves near Naissaar is that several peaks in long waves, apparently corresponding to the same ship and departure time, appear at greatly different time on subsequent days (Fig. 13). A probable reason for this feature is the difference in wave periods on subsequent days that results in large differences of the wave travelling time.

\section{AVERAGE ENERGY AND POWER DENSITY OF SHIP WAVES}

The impact of waves can be quantified in terms of the wave energy and its flux. Traditionally, the wave energy is interpreted as the integral (bulk) energy density in the whole water column (e.g., $\mathrm{J} / \mathrm{m}^{2}$ ) that is proportional to the wave height squared. The wave energy propagates with the group velocity. The product of the wave energy density and of the group velocity equals to the density of the energy flux. The latter is equivalent to the density of the bulk power carried by the wave per unit of length of wave crests (e.g., W/m). While the wave energy is simply proportional to the wave height squared, the energy flux (wave power) takes implicitly into account the wave periods since longer waves generally have higher group velocities.

In order to evaluate the average energetic properties of ship waves, it must be taken into account that the wave recordings were divided into intervals with a length of 5-35 min. The recording intervals were separated by a pause of 30-76 s (Section 2 and Table 2). Since the pauses were not correlated with the ship timetable, it can be assumed that a record, in general, well represents the wave field parameters during both the recording interval and the subsequent pause. Thus the average ship wave energy and flux were first calculated for each of such time spans. Next, average wave parameters over the total recording time on each day (or subsequent days for longer continuous recordings, Table 2) were obtained as an average over the spans.

Not all departures of fast ferries of a calendar day were traced in several measurement sessions (Table 2). An estimate of daily average parameters of ship waves can be obtained by multiplying the measured values by the ratio of the total number of departures and the recorded traces (coefficient $K_{1}$ in Table 2). Doing this is equivalent to the assumption that the departures of fast ferries, not traced during a measurement day, statistically give an equal contribution to the total ship wave field. This assumption may fail in specific cases, because the wake pattern may strongly depend on the load and vessel trim and navigation details. However, the above has shown that there were no specific time intervals when the wakes were different from those during the rest of the day. Also, the highest wakes appeared more or less randomly on different days.

The latter assumption implicitly means that all the ship waves of a calendar day have been traced within the measurement intervals. To obtain the daily average ship wave energy density and its flux at the measurement sites, the average of these quantities over the total recording time of a day were additionally multiplied, if appropriate, by the fraction of a calendar day covered by recordings (coefficient 
$K_{2}$ in Table 2). The resulting quantities are directly comparable with analogous ones for wind waves. Thus they allow a comparison of the possible influence of ship waves with that of wind waves in a more reliable manner than, for example, a simple count of wave crests or estimates of wave heights. For simplicity, below we shall call these quantities (bulk) energy and power density.

The described procedure obviously can be applied to each Fourier component of the wave field since it is a linear modification of the wave energy and since the result does not depend on the parameters of other wave components. If applied for the spectral energy density calculated for each record, it results in an estimate of the (daily) average wave energy spectra for the measurement sites (Fig. 14). It can be, in principle, directly calculated by applying the FFT to the set of properly prepared pressure recordings. However, the direct calculations presume a very large number of points $\left(\sim 10^{6}\right)$ of the FFT that is not always reasonable.

A basic advantage of such an energy spectrum is that, formally, it allows to discuss the properties of large ensembles of transient ship waves in terms of wave energy spectra. This approach implicitly presumes that ship waves satisfy the linear dispersion relation for surface waves. For large transient waves this assumption may fail. However, rough estimates confirm that the group velocity of ship waves generally matches the predictions of the linear theory.

Comparison of average wave spectra for different sites shows that the waves of different origin were well separated in the spectral domain in weak and moderate wind conditions. Since the wind wave energy spectra typically have a steep slope at the long-wave side of the spectral maximum $\left[{ }^{27}\right]$, the average wave energy spectra in Fig. 14 apparently correctly describe the longer components of ship waves. The wave fields recorded at Aegna and Pringi jetties contained a
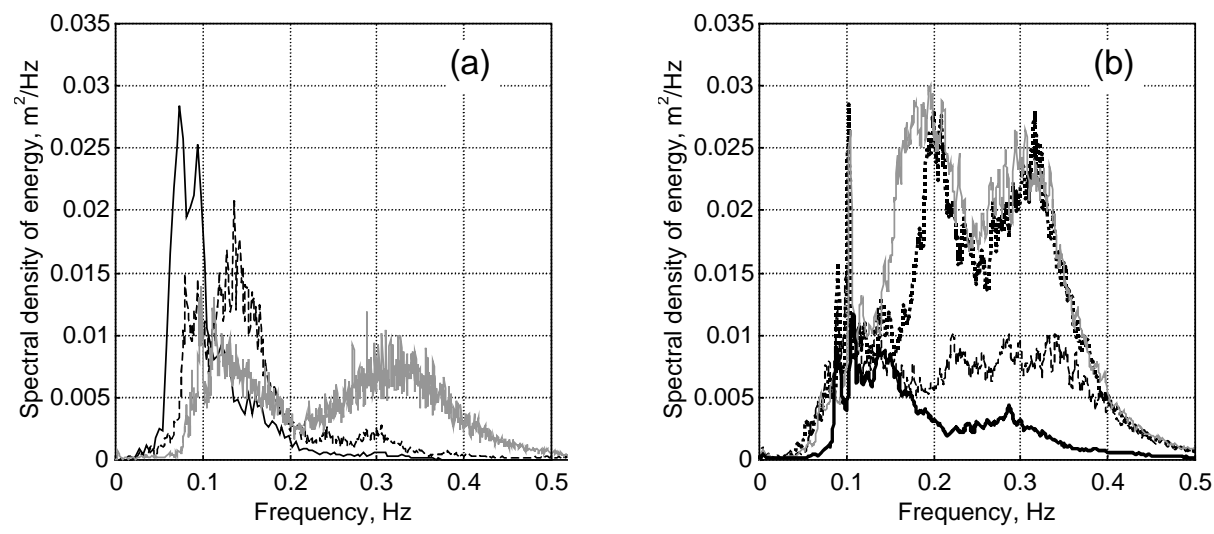

Fig. 14. (a) The daily average spectral energy density at Aegna jetty on 14.04 (solid line), at the Pringi jetty on 12.05 (dashed line) and at the Viimsi museum on 31.05-01.06 (grey line); (b) the daily average spectral energy density at the western coast of Aegna on 17.07 (dotted line), on 18.06 (dashed line) and on 20.06 (grey line), and at Naissaar harbour on 06.-08.08 (bold line). There was a strong gale on 21.06 and the shorter components of the ship wake were indistinguishable from the natural wave background on this day. 
very small amount of the wind wave energy (possibly corresponding to a weak maximum for waves with periods about $3 \mathrm{~s}$ at Pringi jetty). The contribution of wind waves was apparently negligible for waves with periods $>2 \mathrm{~s}(0.5 \mathrm{~Hz})$ at Aegna jetty and for waves with periods $>4 \mathrm{~s}(0.25 \mathrm{~Hz})$ at Pringi jetty. At the Viimsi museum, wind and ship waves had comparable energy whereas wind waves were negligible among waves with periods $>5 \mathrm{~s}(0.2 \mathrm{~Hz})$. At Naissaar, ship waves dominated among waves with periods $>4.5 \mathrm{~s}(0.22 \mathrm{~Hz})$. At the western coast of Aegna, wind waves dominated among waves with periods $<6 \mathrm{~s}$ $(0.17 \mathrm{~Hz})$ but were negligible among waves with periods $>8 \mathrm{~s}(0.125 \mathrm{~Hz})$. The latter property partially reflects the unfavourable wind conditions for ship wave recordings (Table 2) but also suggests that the portion of open sea swell waves was much larger at this site than at the other measurement points.

Although the wave energy spectra in wakes of single ships were very sharply peaked (Figs. 5 and 7), on average the wave energy was distributed much more evenly among the wave components (Fig. 14). The average wave energy spectrum had the most sharply peaked shape near Aegna jetty. Its main maximum corresponded to waves with periods about $14 \mathrm{~s}$ and another maximum to waves with periods about $10 \mathrm{~s}$. The peaks apparently corresponded to the first and the second group of the wake patterns. Owing to particularly calm conditions of that session, the portion of wind waves was very small compared to the ship waves. The overwhelming domination of long wave components in the wave field shows that the portion of waves with periods of 3-5 s generated by hydrofoils and conventional ships was practically negligible in the total ship energy budget.

This distribution had also a double-peaked shape in the measurements at the other sites near the eastern coast of the bay. The ship wave energy maximums were located at clearly smaller wave periods (11 and $7 \mathrm{~s}$ at Pringi jetty, 10 and $8 \mathrm{~s}$ at the Viimsi museum).

A specific feature of all the wave energy spectra at the western coast of Aegna (Fig. 14b) is that it contained two very sharp sub-peaks corresponding to waves with periods of 11-12 s and 9-10 s. Since the fast ferries apparently sail at their cruise speeds near this site, the sub-peaks can be interpreted as showing that the periods of the leading waves were different for different ship types. Another peak corresponds to waves with periods of 6-7 s. This peak is not distinguishable in the wave spectrum on 20.06, because of strong natural wave background.

The distribution of the wave energy had a two-peaked shape also at the Naissaar measurement site. The energy of waves with periods of 6-10 s at Naissaar was comparable with that in the other sites whereas the portion of even longer waves was much smaller. This feature may result from more intense wave-bottom interaction of long waves in the sea area between the ship lane and Naissaar. Another possible reason is that only divergent waves reach the coastal zone of Naissaar.

Thus the major part of the energy of the fast ferries' wakes was concentrated in the wave components with the periods exceeding 6-7 s (Fig. 14). The largest fraction $(77 \%)$ of energy in waves with periods $>8 \mathrm{~s}$ was recorded at Aegna jetty. 
The locations of the spectral peaks of the average energy distribution are greatly different at different sites. The area at Aegna jetty receives a large portion of energy of extremely long waves with periods exceeding $10 \mathrm{~s}$. The neighbouring area at the western coast of Aegna receives some energy of waves with periods of $9-10 \mathrm{~s}$ but mostly wave energy is concentrated in components with $6-8 \mathrm{~s}$. The most energetic waves at Pringi are relatively short (with periods $<9 \mathrm{~s}$ ). This difference suggests that a large part of ship waves, arriving at Pringi jetty, was created when ships were sailing at relatively modest speeds. Notice that the difference of the prevailing periods of the highest parts of the ship wake is a critical issue in the comparison of the influence of natural and anthropogenic waves $\left[{ }^{13,21,31}\right]$.

The double spectral peak in all discussed energy spectra shows that the waves of the different parts of the wake (that are clearly separated in space and time) are also well separated in the spectral domain. The spectral maximum at wave periods $>10 \mathrm{~s}$ apparently corresponds to the leading wave group whereas another maximum for waves with periods $6-8 \mathrm{~s}$ (10 s at Aegna jetty) corresponds to the second group. The third group is not distinguishable in the average spectrum. Although waves with the periods of 3-4 s were frequently, in particular in remote areas, the highest of a wake pattern, energetically this part of the wakes is insignificant. An apparent reason for that is that high and short waves appear relatively seldom, and the duration of their packet is short.

Since in certain sessions it was impossible to extract the shorter part of ship waves from the whole wave field, it was assumed, as the first approximation, that the energy spectrum of ship waves with periods $2.5-8 \mathrm{~s}$ at all sites coincided with that at Aegna jetty on 14.04. Thus the bulk energy density of ship waves in this period range was set to $4 \mathrm{~J} / \mathrm{m}^{2}$. This approximation generally underestimates the portion of ship wave energy in this range, because at Aegna jetty the energy has been concentrated in uncommonly long waves. However, the possible error should not exceed $2-3 \mathrm{~J} / \mathrm{m}^{2}$ and lies in the range of the variability of ship wave patterns.

The bulk ship wave energy density varies from 9 to $16 \mathrm{~J} / \mathrm{m}^{2}$ at different locations of the eastern coast (Table 2). It is the highest near Aegna jetty, slightly less at Pringi jetty and somewhat smaller at other measurement sites. Somewhat surprisingly, it is only a little less in the coastal area of Naissaar $\left(8.5 \mathrm{~J} / \mathrm{m}^{2}\right)$ although the maximum long wave heights at Naissaar were much less than those near the Viimsi Peninsula or Aegna.

The bulk ship wave power was calculated based on the assumption that the energy of the whole wave field propagates with the group velocity of the wave, which frequency equals to the mean frequency of the whole wave field. The bulk wave power varies from 50 to $100 \mathrm{~W} / \mathrm{m}$ and in specific locations may even slightly exceed $100 \mathrm{~W} / \mathrm{m}$ in the coastal area of Tallinn Bay (Table 2). Since the periods, wavelengths, and group velocities of the most energetic ship waves exceed those of wind waves, the relative role of ship waves in the energy flux balance generally is much larger compared to that in the energy balance $\left[{ }^{22}\right]$. 


\section{RESULTS AND DISCUSSION}

In Tallinn Bay, both the wave heights and periods are moderate during the typical wind conditions of the relatively calm spring and summer seasons (when weak and moderate winds prevail). The significant wave height exceeds $1 \mathrm{~m}$ if mean wind speed exceeds $10 \mathrm{~m} / \mathrm{s}$ during a few hours. The mean wave periods are $3-4 \mathrm{~s}$ in such wind conditions but a swell with a typical frequency of 4-5 s may appear if such winds persist at least for $4-5 \mathrm{~h}$. Gales with the wind speed exceeding $14-15 \mathrm{~m} / \mathrm{s}$ are uncommon and result in the significant wave height about $2 \mathrm{~m}$. The wave periods vary largely according to the duration of the gale but the mean period normally does not exceed $4-5 \mathrm{~s}$. Swell-dominated wave fields infrequently appear after strong storms. The properties of the wave field during the windy autumn and winter seasons may considerably differ from the described one owing to possible differences in the wind regime.

Waves caused by fast ferries generally are higher than those excited by hydrofoils or conventional ferries. The heights of waves generated jointly by two or three ships (optionally, in a superposition with a background wind wave field) may reach in extreme cases $1.7-2.3 \mathrm{~m}$ at the $5 \mathrm{~m}$ isobath of the eastern coast of Tallinn Bay. In the remote areas such as the nearshore of Naissaar their height does not exceed $70 \mathrm{~cm}$.

A wake arrives at the eastern coast of the bay (about $2 \mathrm{~km}$ from the ship lane) approximately $10 \mathrm{~min}$ after the ship has passed. Its total duration is about 10-15 min. Most of the recorded wave patterns are apparently generated at the high speed subcritical regime $\left[{ }^{9}\right]$. However, a small number of traces can be related to waves possibly excited in the transcritical regime.

The majority of the wave energy of fast ferries' wakes is concentrated in two parts of the wake patterns. The fragments are well separated in both the time and space domain but also in the spectral domain. The first one is the group of leading waves that have typical periods of 10-15 s and lasts about 4-5 minutes. These waves usually are the highest and have the largest periods. Their daily maximum height at a depth of $5 \mathrm{~m}$ is $80-108 \mathrm{~cm}$, depending on the site. Such waves do not exist in natural conditions in the area in question.

The highest leading waves have been measured near Aegna jetty in a relatively deep water $(6.7 \mathrm{~m})$. Theoretically, this area may be hit by large bow waves generated by ships sailing at a near-critical speed. The number of wave crests with the heights close to $1 \mathrm{~m}$ may be many tens per day in specific parts of the coast. The typical height of the highest waves from individual wake patterns, however, is moderate and in most cases equals to $60-80 \mathrm{~cm}$.

In a more remote coastal zone of Naissaar (about $8 \mathrm{~km}$ from the ship lane) the leading waves arrive several tens of minutes after a ship has passed. Their maximum and typical height is 47 and $20-30 \mathrm{~cm}$, respectively.

Another energetically important wake component consists of the waves of the second wave group, arriving a few minutes after the leading waves. Their periods (7-8 s, at times up to $10 \mathrm{~s}$ ) and amplitudes are generally less than those of the 
leading waves. However, the bulk energies of these groups are comparable with each other.

The closing part of a wake optionally consists of short and steep waves with periods of 3-4 s. They may arrive much later than the leading waves. In a few cases (more frequently at Naissaar) they are the highest part of a wake pattern. The duration of this segment is about one minute. It consists of about ten to fifteen wave crests. It carries a small fraction of the total wake energy but may remain compact during a long time. Owing to its small wavelengths, it may penetrate into the vicinity of the shoreline and is visually easily detectable. This group may be formed as a result of (possibly non-linear) interaction of divergent and transverse waves $\left[{ }^{9}\right]$ but the actual mechanism of their generation is not clear.

A prime factor in many wake problems is the increase of the wave height while the wake proceeds from deep into shallow water. This increase is determined by the ratio of the wavelength to the water depth. The conservation law of the wave energy flux prescribes that the height increase is roughly inversely proportional to the decrease of the group velocity. Therefore the increase in height may be much stronger for the long waves generated by a fast ferry than for the shorter ones of a conventional ship or for the short-wave part of the wake. For example, New Scientist reported 22.09.1999 that in August 1999, holidaymakers on a beach at Felixstowe, three miles north of Harwich, UK, were forced to "flee for their lives when enormous waves erupted out of a millpondsmooth sea". Effects of wave focusing due to a variable bathymetry may additionally modify such events and their spatial and temporal distribution.

The measurement techniques used did not allow to determine the wave profile. Relevant measurements were performed in September $\left.2001{ }^{12}\right]$ but the details are neither published nor available electronically. The shape of the pressure signal suggests that the leading waves of a wake are asymmetric: the crest elevation clearly exceeds the depth of the trough. The single waves formed at critical velocity may also have features of cnoidal or solitary waves. The near-bottom velocities created by these waves may be essentially larger than predicted by the linear theory. Another important issue is that the slope of the water surface in cnoidal or soliton-like waves may exceed that in linear surface waves. Therefore such waves may be particularly dangerous for small boats. The possibility of forming highly monochromatic packets of short waves (resembling envelope solitons) means that the most dangerous short but steep waves might arrive after many tens of minutes (or even more than an hour) after the leading waves.

\section{ACKNOWLEDGEMENTS}

This study was mostly performed in the framework of the project "The influence of ship wakes on beaches of the Viimsi Peninsula and Naissaar and Aegna islands, and the possibilities of its neutralising" (financed by the Estonian Environmental Investment Centre) and partially supported by the Estonian Science Foundation (grant No. 4025). The authors are grateful to A. Raja for his 
contribution to the field wave measurements and to T. Kõuts for presenting the Miiduranna wind data.

\section{REFERENCES}

1. Rzheplinsky, G. V. and Brekhovskikh, Yu.P. (eds.). Wave Atlas for Gulf of Finland. Gidrometeoizdat, Leningrad, 1967 (in Russian).

2. Orlenko, L. R. (ed.) Studies of the Hydrometeorological Regime of the Tallinn Bay. Gidrometeoizdat, Leningrad, 1984 (in Russian).

3. Liiv, T. and Liiv, U. Saaremaa deep harbour layout design and computer simulation of the wave climate and sediment transport. Proc. Estonian Acad. Sci. Eng., 2001, 7, 174-192.

4. Liiv, T. and Liiv, U. Muuga lahe lainetuse kaart. In Muuga sadama merekeskkonnamõju seire 2002, hüdrodünaamika (Kõuts, T., ed.). Marine Systems Institute, Tallinn, 2002, 59-82.

5. Soomere, T. Wave regimes and anomalies off north-western Saaremaa Island. Proc. Estonian Acad. Sci. Eng., 2001, 7, 157-173.

6. Soomere, T. Tallinna lahe looduslike lainete režiimist. Publicationes Instituti Geographici Universitatis Tartuensis, 2003, 93, 227-241.

7. Kofoed-Hansen, H. and Kirkegaard, J. Technical Investigation of Wake Wash from Fast Ferries. Report No. 96-5012. Danish Hydraulic Institute, Copenhagen, 1996.

8. Kofoed-Hansen, H. and Mikkelsen, A. C. Wake wash from fast ferries in Denmark. In Proc. Fourth International Conference of Fast Sea Transportation. Sydney, 1997. Baird Publications, Hong Kong, 1997, vol. 1, 471-478.

9. Kirk McClure Morton. Investigation of High Speed Craft on Routes Near to Land or Enclosed Estuaries. Research Report JR226. The Maritime and Coastguard Agency, UK, 1998.

10. Forsman, B. High-speed ferries - environmental impact and safety assessment. PIANC Bulletin, No. 96, 1997, 23-24.

11. Parnell, K. E. and Kofoed-Hansen, H. Wakes from large high-speed ferries in confined coastal waters: Management approaches with examples from New Zealand and Denmark. Coastal Manag., 2001, 29, 217-237.

12. Peltoniemi, H., Bengston, A., Rytkönen, J., and Kõuts, T. Measurements of fast ferry waves in Helsinki-Tallinn route. In Abstracts, Symposium "The changing State of the Gulf of Finland Ecosystem". Tallinn, 2002, 32.

13. Soomere, T., Elken, J., Kask, J., Keevallik, S., Kõuts, T., Metsaveer, J., and Peterson, P. Laevaliikluse purustav mõju Viimsi poolsaare, Aegna ja Naissaare randadele ning selle neutraliseerimise võimalused. Res. Report. Marine Systems Institute, Tallinn, 2002.

14. Varyani, K. S. and Krishnankutty, P. Wave Wash of Stena Explorer in Dublin Bay. EU Project TOHPIC, Document No 1.2.08.01, 2002.

15. Varyani, K. S. and Krishnankutty, P. Wave Wash of NGV Liamone in Nice Port. EU Project TOHPIC, Document No 1.2.08.02, 2002.

16. Varyani, K. S. and Krishnankutty, P. Wave Wash of INCAT96 in Barcelona. EU Project TOHPIC, Document No 1.2.08.03, 2002.

17. Whittaker, T. J. T., Doyle, R., and Elsäßer, B. An experimental investigation of the physical characteristics of fast ferry wake. In 2nd International Euroconference on Highperformance Marine Vehicles HIPER'01. Hamburg, 2001. Technical University HamburgHarburg, 2001, 480-491.

18. Sörensen, R. M. Ship-generated waves. Adv. Hydrosci., 1973, 9, 49-83.

19. Chen, X.-N. and Sharma, S. On ships at supercritical speeds. In 21st Symposium on Naval Hydrodynamics. Trondheim, 1996. National Academy Press, Washington, D. C., 1997, 715-726.

20. Hannon, M. A. and Varyani, K. S. The wash effect of high speed ferries in coastal and inland waterways. In International Conference on Coastal Ships and Inland Waterways. London, 1999. RINA, London, 1999. CD. 
21. Kirkegaard, J., Kofoed-Hansen, H., and Elfrink, B. Wake wash of high-speed craft in coastal areas. In Coastal Engineering 1998. Proc. 26th International Conference. Copenhagen, 1998 (Edge, B. L., ed.). American Society of Civil Engineers, 1999, vol. 1, 325-337.

22. Soomere, T., Elken, J., Kask, J., Keevallik, S., Kõuts, T., Metsaveer, J., and Peterson, P. Fast ferries as a new key forcing factor in Tallinn Bay. Proc. Estonian Acad. Sci. Eng., 2003, 9, 220-242.

23. Kask, J., Talpas, A., Kask, A., and Schwarzer, K. Geological setting of areas endangered by waves generated by fast ferries in Tallinn Bay. Proc. Estonian Acad. Sci. Eng., 2003, 9, 185-208.

24. SBE26 Seagauge Wave and Tide Recorder. Operating manual. Sea-Bird Electronics, Inc., Bellevue, Washington, 2002.

25. IAHR working group on wave generation and analysis. List of sea-state parameters. J. Waterway, Port, Coastal, Ocean Eng., 1989, 115, 793-808.

26. Kahma, K. On two-peaked wave spectra. Finnish Marine Res., 1981, 248, 87-116.

27. Komen, G. J., Cavaleri, L., Donelan, M., Hasselmann, K., Hasselmann, S., and Janssen, P. A. E. M. Dynamics and Modelling of Ocean Waves. Cambridge University Press, Cambridge, 1994.

28. Grimshaw, R., Pelinovsky, D., Pelinovsky, E., and Talipova, T. Wave group dynamics in weakly nonlinear long-wave models. Physica D, 2001, 159, 35-57.

29. Forsman, B. From bow to beach. SSPA Highlights, 2001, No. 3, 4-5.

30. Peterson, P., Soomere, T., Engelbrecht, J., and van Groesen, E. Soliton interaction as a possible model for extreme waves in shallon water. Nonlinear Processes in Geophys., 2003. Forthcoming.

31. Soomere, T. and Kask, J. A specific impact of waves of fast ferries on sediment transport processes of Tallinn Bay. Proc. Estonian Acad. Sci. Biol. Ecol., 2003, 52, 319-331.

\section{Tuule- ja laevalainete mõõtmised Tallinna lahel}

\section{Tarmo Soomere ja Kalev Rannat}

On esitatud Tallinna lahe erinevates rannaosades 2001-2002 tehtud looduslike ja laevalainete mõõtmise tulemused. Looduslike lainete põhilisi parameetreid ning nende ühemõõtmelise energiaspektri omadusi on hinnatud erinevates tuuletingimustes. On analüüsitud laevalainete pakettide struktuuri, maksimaalseid ja tuiüpilisi parameetreid ning nende varieeruvust lahe mitmes osas. Suurte kiirlaevade tekitatud lained on üldiselt kõrgemad kui tiiburite ja klassikaliste parvlaevade käigulained. Lahe idaranna lähistel $5 \mathrm{~m}$ sügavuses vees esineb iga päev kümneid ligikaudu $1 \mathrm{~m}$ kõrguseid laineid. Üksikutes rannaosades ulatub kiirlaevalainete kõrgus 1,7-2,3 meetrini. Suurima energiaga kiirlaevalainete perioodid on sageli 10-15 s; selliste parameetritega looduslikke laineid Tallinna lahel ei esine. Laevalainete keskmine energiatihedus ja selle voog (võimsustihedus) varieeruvad lahel suhteliselt vähe. Eri rannaosi mõjutavad siiski võrdlemisi erinevate parameetritega lained. 